\title{
JUVENIL OU JOVEM? CONSTRUÇÕES DE SENTIDO DA LITERATURA BRASILEIRA ATUAL PARA JOVENS
}

\section{TEEN OR YOUNG ADULT? CONSTRUCTION OF MEANING IN RECENT BRAZILIAN YOUTH LITERATURE}

Regina Peixoto Carneiro ${ }^{1}$

Cássia Farias²

\begin{abstract}
Resumo: Este artigo trata da produção de novos autores brasileiros voltadas para um público jovem, e a aproximação dessas obras com a literatura young adult (YA) em língua inglesa. A correlação entre as duas literaturas é feita pelos próprios autores e pelos leitores, e o trabalho apresenta uma análise do uso do termo YA, bem como de alguns livros recentes a fim de investigar esse fenômeno.
\end{abstract}

\begin{abstract}
This article discusses the work of new Brazilian authors that write for a young audience and the association of these books with the YA literature written in English. The correlation between these literatures is made by the authors and by the readers, and this paper presents an analysis of the use of the term YA, as well as some recent books in order to investigate this phenomenon.
\end{abstract}

Palavras-chave: Literatura juvenil; Literatura brasileira; Terminologia.

Keywords: Young adult literature; Brazilian literature; Terminology.

Nos últimos anos, surgiram novos autores nacionais que são e falam para um público jovem. Eles vêm conseguindo destaque e atraindo leitores - em sua maioria adolescentes -, mas em vez de usar o rótulo juvenil, classificam suas obras como literatura para jovens adultos ou simplesmente young adult, emprestado do inglês. A escolha desse termo aponta para a influência de obras estrangeiras que dominam nosso mercado editorial, e não se limita aos autores, sendo usado também por leitores, editoras e veículos de comunicação.

A observação desse fenômeno despertou para a necessidade de uma investigação sobre essa produção, especialmente no que se refere ao uso do termo young adult e às construções de sentido em torno dele, uma vez que parece haver uma rejeição do rótulo de juvenil e infantojuvenil. O propósito

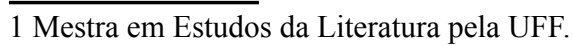

2 Doutoranda em Literatura Comparada na UFF.

Revista Crioula - n 25 - Literaturas de língua portuguesa para crianças e jovens 
deste artigo, então, é fazer uma discussão sobre essas obras buscando mapear o que se entende, no Brasil, como literatura young adult, e se ela seria diferente de uma literatura chamada de juvenil. Para isso, iremos explorar os discursos acerca do tema, passando por aqueles de selos jovens de editoras a discussões que esses livros movimentam em redes sociais. Por fim, pretende-se analisar algumas obras brasileiras com publicação recente, verificando em que pontos elas se aproximam dessa literatura young adult.

O primeiro ponto a se discutir, então, é justamente o que é literatura young adult. Popularmente conhecida como YA, este subsistema literário se consolidou em meados do século XX. Atualmente, é amplamente aceito que a literatura young adult se caracteriza por ser escrita e "especificamente comercializada para um público adolescente" (TRITES, 2000, p.7, tradução nossa), sendo o termo young adult (jovem adulto, em tradução direta) usado para se referir a "aqueles indivíduos de doze a dezoito anos" (CARTER, 1994 apud CART, 2010, p.7, tradução nossa), funcionando como uma espécie de sinônimo para adolescente. Existe alguma divergência entre os estudiosos da área sobre qual é a faixa etária precisa, mas esse intervalo aparece na maioria das definições. Pode-se entender, então, baseado no público-alvo e nas condições de produção, que a literatura YA é o nome dado nos países de língua inglesa para literatura juvenil.

No Brasil, o termo young adult circula livremente entre os leitores em meio virtual, chegando às instâncias do mercado livreiro. Um exemplo disso foi o hotsite criado pela loja virtual da Livraria Cultura em 2015 (CARCIOFI, 2015), que podia ser acessado quando se pesquisava os termos young adult, e que trazia uma imagem com uma breve definição do que seria essa literatura. Sob o título "Literatura Young Adult", a imagem mostra John Green e Gayle Forman, autores estadunidenses conceituados, e Paula Pimenta, autora nacional que, à época, já tinha muitas obras publicadas. A junção desses escritores sobre um mesmo "rótulo" parece indicar um esforço de construir para o leitor uma conexão entre a literatura juvenil brasileira e a estadunidense - ou talvez reflita uma relação que os próprios jovens já estariam fazendo.

Se essa relação ainda era envolta em conjecturas, atualmente ela parece ter se cristalizado. Um exemplo é a matéria “"A pluralidade sexual está na ficção e na vida dos leitores', dizem autores e editores de livros para jovens", publicada pelo $O$ Globo, em 2019, após a polêmica envolvendo a circulação dos livros LGBTQIA+ na Bienal do Livro do Rio. Ao falar sobre o autor Vitor Martins, o jornalista Ruan Gabriel afirma que os "dois romances de Martins, exemplificam como a literatura juvenil (hoje chamada de Young Adult) não só saiu do armário como também alcançou leitores os mais diversos" (GABRIEL, 2019). Esse uso, por parte da mídia, reproduz o discurso dos próprios autores e leitores dessas obras.

Entre os booktubers brasileiros, a expressão young adult é comumente usada para se referir 
a livros com protagonistas jovens, tanto brasileiros quanto internacionais, como exemplificado por vídeos como "Um milhão de finais felizes | YA Nacional”, de Eduardo Cilto (2019), sobre o livro de Martins. Na plataforma Goodreads, é possível encontrar listas feitas por leitores, e já existem algumas relações que incluem livros nacionais. Entre elas, uma lista chamada "YA brasileiro contemporâneo", com a descrição "Lista de livros Young Adult (...) escritos por autores brasileiros", criada por Iris Figueiredo, um dos nomes dessa geração.

A autora Clara Alves escreveu sobre o livro O Amor não é óbvio, de 2019: "Elayne Baeta é a cara do YA nacional: texto divertido, cheio de reflexões, com personagens reais. É, sem dúvidas, o que eu gostaria de ter lido quando era adolescente." (ALVES, 2019). O comentário de Alves mostra que, tão recente quanto 2019, parece existir uma "cara do YA nacional", apontando que o termo é de uso corrente, facilmente reconhecível pelos leitores e pelo mercado editorial, uma vez que se encontra na contracapa de um livro publicado por uma das maiores editoras do Brasil.

O autor Vitor Martins, ao ter seu livro indicado em uma matéria da Folha de São Paulo, comentou no Twitter: "a validação nesse sentido vem do fato de estar em um meio de comunicação grande que listou um livro YA sem EVIDENCIAR que é YA. sem o clássico 'apesar de ser um livro juvenil...' antes do texto." (MARTINS, 2018a), classificando assim seu livro Um milhão de finais felizes (2018c).

A Galera Record afirma ser dedicada a "Literatura sem fronteiras de idade ou conceitos preestabelecidos" e que "Sua proposta era, e continua sendo, atender ao público de 12 a 20 e muitos anos - leitores ávidos por novidades que falem a sua língua e retratem temas com os quais se identifiquem." (RECORD, 2019a). A Seguinte proclama, no final de seu site, ser "o selo jovem da Companhia das Letras" (SEGUINTE, 2020).

Além, do uso de jovem, os termos YA e young adult (e sua tradução) também aparecem. A editora Literalize, dedicada a obras de fantasia, se define em seu site como: "nosso foco editorial é a fantasia jovem adulta." (LITERALIZE, 2019). No entanto, em seu Twitter, se descrevem de outra maneira: "O melhor da fantasia YA para jovens e adultos" (LITERALIZE, 2019). Sobre seu selo jovem, a Rocco afirma: "Com forte presença de mercado, o selo Rocco Jovens Leitores tornou-se referência no segmento juvenil e young adult" (ROCCO, 2014), o que demonstra uma consciência de que são manifestações distintas.

Percebe-se que não existe um consenso por parte das editoras sobre uma nomenclatura, por vezes variando seu uso em diferentes plataformas da mesma empresa. É possível observar, porém, que a palavra jovem costuma ser privilegiada e que, no geral, existe uma recusa em delimitar a faixa etária englobada nos selos, seja porque ela é de fato extensa, como no caso da Seguinte e da Record, 
seja para não alienar leitores variados que venham a se interessar por suas obras ("Literatura sem fronteiras de idade"). Notadamente, há uma baixa incidência da palavra juvenil. Na verdade, nos diversos discursos mostrados, o termo literatura juvenil raramente é utilizado.

Os fatos elencados até esse momento parecem apontar que, para o leitor atual, literatura young adult e literatura juvenil são, de fato, duas coisas distintas. Taty Leite, do canal de YouTube Vá ler um livro, perguntou em seu Twitter: "Quem é o maior nome de literatura YA aqui no Brasil pra vocês? Contemporâneo E vivo, hein..." (LEITE, 2019). Muitos autores novos foram mencionados, mas nomes como Thalita Rebouças e Paula Pimenta também surgiram, gerando dúvidas.

@ RebecaKim_: Iris Figueiredo (não sei se Thalita Rebouças é muito YA, mas tbm vale) (...)

@LaisPNS: No momento, para mim, é a Carina Rissi. Não entendi a Paula Pimenta nas respostas. Ela não é infanto-juvenil?

@andersonvbranco: Os personagens dela cresceram durante os livros, acho, assim como a classificação dos livros. (LEITE, 2019)

Essas duas autoras são anteriores à geração das que tratamos aqui, o que pode ser um possível motivo para essa confusão. Clara Alves, em seu Twitter, também chama Rebouças de YA (ALVES, 2020), mas no site da Rocco ela é descrita como sendo um "fenômeno da literatura juvenil nacional" (ROCCO, 2014). Podemos então, observar duas situações: uma é o uso de YA para se referir a qualquer produção feita para um certo público leitor, e a outra é o uso do termo apenas para os autores mais recentes.

Mais interessante para essa discussão, porém, é o caso de Paula Pimenta, que, como visto, em 2015 foi chamada de YA pela livraria Cultura, e aparece como juvenil no site de sua editora. Apesar da série Fazendo meu filme ter sido iniciada em 2008, é possível perceber em seus livros uma influência da literatura juvenil em língua inglesa, tanto pelas referências a séries e filmes quanto pelo projeto gráfico, que se assemelha muito com o de obras traduzidas na época.

O diálogo citado entre os usuários@LaisPNS e @andersonvbranco revela que há um entendimento por parte dos leitores de que um livro, para ser considerado YA, deveria ser mais maduro do que um livro juvenil, ou, como chamou a usuária, infantojuvenil. Isso pode ser observado na menção a Carina Rissi, cujos livros têm uma clara filiação ao gênero ficção romântica, e que é publicada pela Verus, que se considera “[u]ma das pioneiras na literatura New Adult no Brasil” (RECORD, 2019b), sendo o new adult um gênero voltado para um público mais adulto, e que será abordado mais adiante. 
O apagamento do termo juvenil parece estar relacionado com a utilização, por vezes confusa, de infantojuvenil. Na reportagem de Gabriel, os termos juvenil e infantojuvenil parecem ser usados como sinônimos, com a reportagem dizendo que a agência literária Página 7 é "especializada em autores infantojuvenis" (GABRIEL, 2019), sendo que a própria agência declara que sua missão é "lançar autores nacionais que escrevem para o público juvenil e jovem adulto" (PÁGINA 7, 2016). A editora Seguinte, ao parabenizar suas autoras Clara Alves e Luisa Geisler pelo Selo Cátedra, afirma que se trata de um prêmio "oferecido por um grupo de especialistas da PUC-Rio para os melhores livros infantis e infantojuvenis publicados aqui no Brasil." (SEGUINTE, 2020), sendo que a própria editora se entende como um "selo jovem". Esses são apenas alguns dos exemplos que podem ser encontrados, e mostram como, para muitos, infantojuvenil e juvenil podem ser usados de forma intercambiável, sendo visto como sinônimos.

A partir do momento em que esses dois termos são aglomerados, é como se uma lacuna fosse criada, em que uma literatura propriamente juvenil não existisse. Um exemplo disso é o concurso CLIPOP:

Nós da editora Seguinte criamos este concurso para incentivar a escrita de obras de ficção voltadas para o público jovem. Nosso objetivo é buscar novas vozes na literatura juvenil nacional $(\ldots)$

Como se inscrever

-Ser voltada para o público infantojuvenil (8 a 12 anos) ou jovem adulto (13 a 18 anos) (CLIPOP, 2019)

Nossos grifos servem para mostrar essa falta de padronização encontrada no uso dos termos; “jovem" e "juvenil" parecem ser usados aqui para significar a mesma coisa, mas, ao chegar nos requisitos do concurso, percebe-se que essa não é a realidade. Primeiro porque se fala em obras para pessoas de 8 anos - considerados jovens apenas em um sentido amplo -, e segundo porque o termo juvenil é abandonado. A faixa etária entre 13 e 18 anos é correspondente com a faixa abarcada pelas literaturas young adult e juvenil, mas se optou por utilizar jovem adulto. É possível argumentar que esse exemplo, por se tratar de uma editora, não é muito significativo, uma vez que eles podem apenas ter escolhido a opção que tinha um apelo de marketing maior. Existem, porém, outras instâncias desse uso. 
O termo jovem adulto começou a se popularizar por ser tradução direta de young adult - que têm grande influência no mercado brasileiro de livros. Em seu vídeo "Gêneros Literários: Jovem Adulto, New Adult, Romance (e mais)" (2017), a booktuber Paola Aleksandra apresenta alguns "gêneros" que se baseiam na faixa etária do leitor. Começando pelo infantil, entre 7 e 10 anos, e passando pelo infantojuvenil, para pré-adolescentes, Paola também faz o salto para o jovem adulto e o jovem adulto maduro, que, segundo ela, são para o público jovem e se diferenciam principalmente pelos temas abordados, que seriam mais sérios em sua variação madura - mas essa distinção não é amplamente utilizada, sendo uma criação dela.

Juan Jullian, autor de Querido ex, (que acabou com a minha saúde mental, ficou milionário e virou uma subcelebridade) (de agora em diante Querido ex), de 2019, em entrevista no podcast Não me critica, define sua obra como YA. Em um certo momento da entrevista, acontece o seguinte diálogo com um dos apresentadores:

J: YA é o young adult, vem do inglês, que é o livro pra jovem adulto. Então John Green, David Levithan, essa galera aí. É o termo que a gente usa, é mais mercadológico do que qualquer outra coisa, né. Mas é, livro pra jovens adultos, assim.

A: É, que passa por uma, tipo, é aqueles que você tá se identificando enquanto tá crescendo, mesmo.

J: Isso, é sobre transformação, sobre descobertas, você quer descobrir o seu lugar no mundo, quem que eu sou...

A: é mais maduro do que infantojuvenil, pelos temas que abordam. (NMC, 2019)

O apresentador e o escritor associam o termo YA ao público "jovem adulto”, em vez de adolescentes. Eles também se referem a temas presentes nesses livros, como crescimento e identificação, e não a uma faixa etária. Eles contrapõem o "livro pra jovem adulto" ao "infantojuvenil", não mencionando o termo juvenil.

Ao analisar o que foi exposto até aqui, podemos começar a traçar uma noção do que está sendo construído como YA nacional por esses diferentes agentes. Nota-se que se destina a um público jovem, não necessariamente adolescente - o que pode ser percebido, por exemplo, ao analisar a descrição do selo jovem da Record, Galera, que aponta seu público-alvo como sendo de "122 a 20 e muitos anos", alegando que é "sem fronteiras de idade" (RECORD, 2019a) -, buscando alcançar uma faixa etária mais ampla. Isso se reflete nos personagens de muitos dos livros YA publicados nos últi- 
mos anos no Brasil, como Um milhão de finais felizes, em que o principal tem uns 20 anos; Você tem a vida inteira, de Lucas Rocha, de 2018, que tem três narradores, com 20, 22 e 25 anos; e Céu sem estrelas, de Iris Figueiredo, de 2018, tem uma protagonista 18 anos que está iniciando a faculdade. Mesmo quando os protagonistas são adolescentes, eles tendem a ser mais velhos, em torno de 16-17 anos, como em Conectadas ou $O$ amor não é óbvio.

Como visto no podcast, os aspectos temáticos também são importantes para caracterizar essa literatura YA. O conteúdo é visto como mais maduro, seja pela abordagem, seja por esses autores enxergarem suas obras como possível espaço de reflexão. No Twitter, Martins criticou a empresa TAG, um clube de assinatura de livros, por ter afirmado em um e-mail para os assinantes que a caixa dedicada a "literatura que faz pensar e desafia o leitor a sair de sua zona de conforto" (MARTINS, 2018b) não enviaria livros young adult. Para o autor, "uma empresa que diz que literatura YA não faz pensar desrespeita não só os autores e as editoras mas, principalmente os leitores", e afirmou que:

atualmente a literatura YA é uma das poucas que tem tido a coragem de se posicionar e dar nome aos bois. falar sobre RACISMO, HOMOFOBIA, GÊNERO, CULTURA DE ESTURPO (sic) etc sem maquiar o tema e ainda assim se colocar como um livro comercial que vai para as prateleiras das livrarias. (MARTINS, 2018b)

A literatura YA nacional, então, não se deixa limitar por tabus ou pelo que se consideraria apropriado para um público jovem. Esses livros apresentam uma variedade de temáticas, que passam desde conflitos do dia a dia, como amor e amizade, a assuntos considerados "pesados", como saúde mental, homofobia e ISTs. É, em muitos momentos, uma literatura engajada, abordando questões de importância social e com foco na representatividade.

Começa, então, a se construir uma imagem de como essa literatura YA é percebida pelo público e pelos autores. É interessante, aqui, voltar ao hotsite da Livraria Cultura, que trazia um breve texto sobre essas obras: "é uma verdade universalmente reconhecida que nós, quase sempre, acabamos por buscar o romance em cada livro que lemos. (...) quem sabe, você não encontra aqui o romance que tanto deseja". Essa descrição, que traz o romance como o principal elemento dessas narrativas, não só não se aplicava aos livros que eles mesmos selecionaram como está muito distante da visão atual sobre a literatura para jovens (adultos). A fala de Martins aponta que, para ele, a literatura YA vai além de histórias de amor envolventes, trazendo temas relevantes para os jovens e para a sociedade. Apesar de muitos terem sim um tom leve e do romance se fazer presente em todas as obras citadas até agora, isso não significa que os assuntos mais sérios são deixados de lado ou não são tratados com responsabilidade. Entende-se que não é uma leitura incapaz de criar reflexão, e que ela ser comercial 
e acessível não se reflete em sua qualidade e potencial. A thread de Martins aponta para um preconceito recorrente quanto ao YA (e contra a literatura juvenil em geral, seja no contexto estadunidense ou no nacional), de que se trata de uma "literatura menor", ao que leitores e autores vêm se posicionando bastante contra.

Esse preconceito pode ser sentido na academia e na sociedade em geral, gerando uma possível contradição. O termo (infanto)juvenil parece vir acompanhado de toda uma carga negativa, de obras simplórias, o que não é real. Luft, ao fazer um panorama da literatura juvenil premiada no século XXI, aplica a elas as linhas temáticas de Teresa Colomer e mostra que a literatura nacional tem um grande foco no psicológico dos protagonistas, - ao trazer "a abordagem de conflitos familiares, amorosos, bem como a tematização de questões polêmicas e presentes na vida do jovem atual" (2010, p.122) e que "apresentam um sentido político e ideológico" (2010, p.125), trazendo ainda denúncias sociais relevantes - deixando claro como esse preconceito com a literatura juvenil é infundado, e não leva em conta o conteúdo real de muitas dessas obras. Entretanto, ao olhar para as obras analisadas por Luft, percebe-se que são livros cujo público-alvo é, de fato, mais novo, o que as diferencia, pelo menos parcialmente, da produção abordada aqui.

Apesar de infundado, tal preconceito deixa marcas nos próprios leitores. A preferência pelos termos jovem e YA parece indicar uma intenção de se distanciar desse imaginário negativo e de uma literatura percebida como mais imatura, por ser feita para um público mais novo. Quando se analisa o que é dito sobre a literatura (infanto)juvenil e jovem (adulta), porém, nota-se que ambas são entendidas como literaturas focadas em representar as diversas facetas da realidade de seus leitores, com seriedade e profundidade - ou seja, o que diferencia elas não são as temáticas escolhidas, mas sim o que se entende como as vivências e necessidades do público-alvo, que se percebe como sendo diferente.

Depois de discutir o que é o YA nacional, vale ressaltar que o que se entende por este termo não necessariamente corresponde à definição de YA estadunidense, pelo menos em sua concepção acadêmica. Foi dito que a literatura young adult é aquela que se dirige para um público aproximadamente entre os 12 e 18 anos, a partir do que se conclui que esse público mais novo, aparentemente excluído da variante brasileira, é sim contemplado por essa literatura nos EUA. Apesar de existirem algumas diferenças na abordagem e na linguagem utilizada nas obras voltadas para jovens entre 12 e 14 anos, elas são sim YA, seguindo as mesmas estruturas e convenções que obras para leitores um pouco mais velhos.

A faixa etária do YA brasileiro parece se aproximar mais de outro subsistema literário, o new adult (NA). O YA começou a fazer um sucesso cada vez maior com adultos, que, apesar de apreciarem essas obras, sentiam que elas já não atendiam suas questões pessoais. Então, o new adult se popularizou nos EUA como tendo protagonistas levemente mais velhos que YA, de 18 a 20 e poucos 
anos e trazendo temas do interesse de adultos. Amy Patee (2017) usa o termo "adultos emergentes" para se referir a este público, aludindo ao fato de estarem também em um período de transição posterior à adolescência - o fim dos estudos e o início da vida profissional e da responsabilidade financeira, importantes marcos do início da fase adulta. Mais importante para a presente discussão é o conteúdo erótico, uma característica relevante das obras denominadas NA, que contém cenas mais explícitas em comparação com o YA. Em termos de forma, porém, os dois subsistemas literários ainda têm muitas semelhanças.

Esse aumento no número de leitores adultos que leem obras voltadas para adolescentes fez com que o mercado editorial se voltasse para duas direções, uma consequência da outra. A primeira foi o surgimento do NA, cuja presença de conteúdo sexual explícito acabou criando um certo desprezo em um grupo de leitores; a segunda foi a iniciativa das editoras de começar a publicar obras YA pensando nesses leitores adultos, o que se refletiu em protagonistas mais velhos. Sobre essa questão, Michael Cart reflete:

Às vezes me pergunto se passar muito tempo focando no aumento explosivo de leitores adultos de livros YA vai fazer com que as editoras de YA se voltem cada vez mais para o NA, às custas de leitores de YA mais novos, e ouvi alguns bibliotecários e livreiros lamentarem a morte recente do YA com histórias inocentes e protagonistas mais jovens - de 12 a 16 anos. (CART, 2014, tradução nossa).

$\mathrm{O}$ fato de o mercado editorial ter negligenciado essas obras com protagonistas mais jovens gerou diversas críticas por parte da academia e de outros profissionais do livro, uma vez que descaracterizou o que antes se entendia por literatura young adult, que eles temem não mais dialogar com o adolescente. Por um lado, parece ter havido uma expansão da percepção de YA; por outro, as fronteiras entre essas duas literaturas, que já não eram tão bem delineadas, ficaram ainda mais confusas. Os protagonistas têm idades e problemas semelhantes, as temáticas se repetem, os projetos gráficos são similares - e o resultado é que o leitor muitas vezes não sabe o que vai encontrar.

Essa expansão da faixa etária do público leitor de YA também foi observada no Brasil. Porém, apesar de o termo NA já ter sido importado pelo nosso mercado e circular na área editorial, tendo até representantes nacionais, como Carina Rissi, nota-se que não é tão popularizado quanto YA, o que é comprovado pela conversa de tweets já mencionada, que mostra que Rissi é por vezes vista como uma escritora de YA.

Foram apresentadas, até o momento, a percepção e as construções de sentido em torno dessa 
produção nacional atual que se entende como jovem adulta. Mas, afinal, o que se apreende da leitura dessas obras em relação ao seu lugar na literatura?

Com o objetivo de oferecer exemplos atuais sobre esta literatura no Brasil, foram selecionadas algumas obras de destaque que são consideradas YA, seja pelos leitores, seja pelos próprios autores. São elas: Querido ex³, de Juan Jullian; Um milhão de finais felizes (UMDFF) e Quinze dias (2017), ambos de Vitor Martins; e Você tem a vida inteira (VTVI), de Lucas Rocha. Os dois últimos, inclusive, serão lançados nos EUA em 2020, pela editora Scholastic, como YA, mostrando o reconhecimento das obras brasileiras lá fora dentro desse subsistema.

Querido ex é o livro de estreia de seu autor, no qual um jovem universitário escreve cartas a seu ex relembrando os momentos bons e ruins do namoro. $\mathrm{O}$ autor aborda assuntos como baixa autoestima, relacionamento abusivo, violência sexual e relação interracial; apesar da seriedade dos temas, a narrativa é por vezes leve e divertida, com muitas referências à cultura pop.

Entre esses autores, o mais famoso e com mais títulos publicados é Martins. Quinze dias conta a história de Felipe, que vê seus planos de férias frustrados quando a mãe diz que o vizinho, Caio, por quem ele é apaixonado, irá passar quinze dias em sua casa. Ao longo da narrativa, Felipe revela suas questões com autoestima, gordofobia e bullying, e como isso resultou em alguns bloqueios. Em seu segundo romance, UMDFF, temos a história de Jonas, um jovem que começou a trabalhar enquanto decide se quer fazer faculdade. Jonas passa por uma jornada de crescimento e autodescoberta, ao mesmo tempo em que vive seu primeiro relacionamento e precisa lidar com a homofobia de seus pais, religiosos e conservadores.

Em VTVI, primeira obra de Rocha, a narração da história é alternada entre três protagonistas, que têm suas vidas entrelaçadas após um exame de HIV. Ian (22 anos) e Victor (20) se conhecem na sala de espera, onde aguardam pelo diagnóstico. Henrique (25) já vive com o vírus há cinco anos e está indetectável; por intermédio de Victor, auxilia Ian, que se descobre soropositivo. Com uma narrativa divertida e sensível, o enredo envolve drag queens, estigmatização do HIV, aceitação e relacionamentos sorodiscordantes.

Como visto acima, as obras selecionadas têm enredos bastante distintos entre si e protagonistas com idades e vivências variadas. Ainda assim, é possível destacar algumas características em comum, que mostram a influência e elementos da literatura YA de língua inglesa. Alguns desses elementos mostram que essa influência se dá na construção narrativa.

Todos os livros mencionados giram em torno do desenvolvimento pessoal dos personagens, seja tentando lidar com suas questões internas, como autoimagem e inseguranças, ou problemas so3 Utilizamos, para esse trabalho, a versão em e-book lançada em 2019. O livro será relançado em 2020 pela Galera Record e pode sofrer alterações. 
ciais que têm um impacto na sua vida, sendo confrontados com situações que quebram sua rotina e que trazem algum aprendizado a eles sobre si mesmos. Esse tipo de história é recorrente na literatura YA, por conta da influência do Bildungsroman em sua origem, sendo comum narrativas que seguem a estrutura de um evento inicial que instaura um estado de crise que faz com que o protagonista precise fazer uma reavaliação de seu mundo e suas relações (FARIAS, 2016). Em diferentes escalas, todos esses romances apresentam uma variação desse modelo. Um momento importante nessa estrutura narrativa é quando a personagem tem um momento de uma quase epifania em que percebe seu papel como agente transformador de sua vida, e faz um apanhado do processo que passou durante o livro. Isso pode ser visto de forma clara em Quinze dias, quando Felipe, após um momento de reflexão, escreve: "Enquanto penso nisso tudo, sinto que estou perto de descobrir algo grande e esclarecedor sobre mim mesmo." (MARTINS, 2017, pos. 3005). De fato, o jovem consegue ultrapassar seus bloqueios, inclusive relativos ao seu próprio corpo, chegando à conclusão que ele "não é uma bomba" (MARTINS, 2017, pos. 3030). Querido ex também tem um momento semelhante no final a história, quando o protagonista, após passar tanto tempo escrevendo cartas com foco no ex abusivo, consegue enfim se desvencilhar da relação, atingindo uma independência emocional:

O mundo era só meu. Meu para fazer o que quiser. Meu para que eu dê o rumo que eu bem entender para a minha vida (...) Foda-se você. Ali estava eu, sozinho, (...) capaz de tomar a rota que eu quisesse, parar e seguir na hora que eu bem entendesse. E aquele choro virou um riso, que virou gargalhar, que virou um grito de empolgação, de euforia, de liberdade. Os pássaros cantavam, a madrugada me cobria. (JULLIAN, 2019, pos. 1685)

A citação de Jullian aponta outro aspecto do young adult estadunidense na literatura nacional: o trabalho poético com a língua. É comum, nessas obras, longas passagens de texto floreado, com intenso uso de figuras de linguagem. Isso é tão marcante nessas narrativas, que, por vezes, alguns desses livros são criticados por serem pretensiosos e não representarem de forma honesta a fala de jovens. Um outro exemplo desse aspecto estético pode ser visto em VTVI, quando Henrique e suas amigas drag queens arremessam balões de tintas coloridas na casa de seu ex, que revelou sua sorologia na internet. Ao descrever a cena, o jovem intercala as ações com versos da música "O tempo não para", que está tocando: "e quando, por fim, Cazuza canta que vê o futuro repetir o passado e que vê um museu de grandes novidades, arremesso o último balão, que explode na cor vermelha" (ROCHA, 2018a, p.275). Mesmo que essas características citadas pudessem ser influência de uma literatura que não a YA estadunidense, uma vez que não são exclusivas dela, é possível traçar esse paralelo não só por ser uma característica marcante dessa literatura, mas também pelo fato de esses autores se decla- 
ram leitores de YA. Jullian, por exemplo, na já citada entrevista, diz que sua maior inspiração é $A s$ vantagens de ser invisível.

Já foi exposto que o que mais se difere do YA nessa seleção é a idade, visto que a maioria desses protagonistas são adultos, quase todos na faculdade. Resta determinar se esse fator é o suficiente para afastar essas obras do YA e, talvez, aproximá-la do NA, que tem características formais semelhantes. Cada livro, porém, tem suas particularidades quanto a esse assunto.

O primeiro romance de Martins segue o modelo tradicional do YA, tanto em relação à temática quanto à forma. As angústias do protagonista são comuns na adolescência, e a resolução do enredo segue um padrão já estabelecido nesse subsistema. UMFF tem um protagonista mais velho, fora da escola e com um emprego, mas os temas de autoconhecimento e processo de descoberta também são fortes, fazendo com que o livro se encaixe como YA.

O erotismo é um elemento-chave do NA, que se encontra marcadamente ausente das narrativas desses novos autores brasileiros no geral. Normalmente, a sexualidade é tratada de maneira semelhante ao que se observa no YA, sendo mais insinuada do que mostrada, mais voltada para o romântico do que para o sexy. A exceção é Querido ex, em que após uma cena carregada eroticamente, o protagonista narra: "Ele me comeu de quatro" (JULLIAN, 2019, pos. 1047). A escolha de palavras durante o encontro sexual se afasta do que é esperado em uma narrativa YA, o que, somado à idade do protagonista, dentre outros aspectos, faz com que este seja o livro que mais se afasta de um modelo tradicional do young adult.

A estrutura narrativa de VTVI também parece se distanciar do YA, especialmente pela diferença entre seus narradores. Ian e Victor seguem um padrão mais comum de narradores juvenis, principalmente o último, que passa por um notável processo de aprendizado. Henrique, por outro lado, diverge desse modelo: enquanto os outros estão envoltos com a autodescoberta e incertezas sobre si, ele tem segurança em sua identidade, e dá indícios de já ter passado por esse processo que vemos em Victor e Ian. Henrique, aos 25 anos, é independente financeiramente e estabelecido em seu emprego, e a descrição de sua trajetória o coloca mais firmemente no que se entende por adulto. A escolha de ter três narradores com vivências tão distintas põe VTVI no limiar entre o YA e uma literatura mais adulta. Talvez seja por esta razão que o autor, em entrevista à Record, tenha usado o termo "literatura jovem" diversas vezes ao se referir à sua obra, não se comprometendo com o termo YA (ROCHA, 2018b).

Essa tendência em obras recentes de protagonistas mais velhos talvez se dê pela idade desses novos autores, se aproximando de suas vivências - não em termos biográficos, mas na natureza dos temas abordados. As questões representadas podem ser entendidas, então, como questões da juven- 
tude, aqui não como sinônimo exclusivamente de adolescente, mas sim de uma fase da vida que se estende para englobar um momento de transição para a vida adulta, marcado por mudanças.

Jovem é a palavra-chave. Além de unir todas as narrativas mencionadas, ela desponta em meio às confusões terminológicas do cenário brasileiro. De fato, literatura jovem nos parece uma boa expressão para denominar esse fenômeno que tem tentado - e conseguido - se afastar de noções pré-concebidas do que é a literatura infantojuvenil e/ou juvenil. Esse termo é propício, também, para indicar a expansão no público-alvo dessas obras que já ocorreu, e dribla uma carga de preconceitos que parecia haver na utilização de outros nomes. Em comparação ao YA ou o "jovem adulto", originado de uma tradução literal e imprecisa, o uso de "jovem" demonstra uma recusa na estrangeirização; ainda que se note uma influência de fora na nossa literatura, a representação da cultura brasileira se faz presente nessas obras. Assim como o YA estadunidense está passando por um período de reformulação - e incerteza -, esses novos autores estão também reformulando o que é escrever para jovens no Brasil e, com isso, misturam influências que tornam difícil encaixá-los em modelos pré-estabelecidos que não preveem suas particularidades. É possível colocar essas obras sobre o escopo do YA, mas talvez um termo nosso fosse mais significativo.

Este fenômeno é novo e, por isso, a investigação aqui proposta está em seus estágios iniciais. Assim, entende-se que se trata de uma discussão ainda em aberto, uma vez que esses autores são em sua maioria iniciantes e com poucas publicações, não sendo possível prever o rumo que tais produções tomarão. Nesse contexto, nosso objetivo não foi dar respostas concretas ou finais, mas sim propor um debate que pode ser de importância por trazer uma perspectiva acadêmica para obras que já têm comprovado apelo com o público.

\section{Referências}

ALVES, Clara. Conheça meus livros, a thread. Rio de Janeiro, 19 de abril de 2020. Twitter: @altaexposicao. Disponível em: https://twitter.com/altaexposicao/status/1251965089713983488. Acesso em: 09 mai. 2020.

ALVES, Clara. Elayne Baeta é a cara do YA nacional. In: BAETA, Elayne. O amor não é óbvio. Rio de Janeiro: Galera Record, 2019.

CARCIOFI, Sandra. Hotsite/Buscador Literatura Young Adult. Behance, 2015. Disponível em: https://www.behance. net/gallery/31798417/HotsiteBuscador-Literatura-Young-Adult. Acesso em: 22 mai. 2020.

CART, Michael. Young Adult Literature: From Romance to Realism. Chicago: American Library Association, 2010.

CLIPOP. Home. [s.1.], [2019?]. Disponível em: http:/clipop.mystrikingly.com/. Acesso em: 19 mai 2020. 
FARIAS, Cássia. Narrativas de amadurecimento: relações entre o romance de formação e a literatura infanto-juvenil. 158 f. Dissertação (Mestrado em Estudos de Literatura) - Universidade Federal Fluminense, Instituto de Letras, 2016. FIGUEIREDO, Iris. YA brasileiro contemporâneo. Goodreads, 18 de outubro de 2017. Disponível em: https://www. goodreads.com/list/show/116769.YA brasileiro contempor neo. Acesso em: 09 mai. 2020.

GABRIEL, Ruan de Sousa. 'A pluralidade sexual está na ficção e na vida dos leitores', dizem autores e editores de livros para jovens. O Globo, 09 de setembro de 2019. Disponível em: https://oglobo.globo.com/cultura/livros/a-pluralidade-sexual-esta-na-ficcao-na-vida-dos-leitores-dizem-autores-editores-de-livros-para-jovens-23937432. Acesso em: 01 mai. 2020.

GÊNEROS LITERÁRIOS: Jovem Adulto, New Adult, Romance (e mais), 2017. 1 vídeo ( 8 min). Publicado pelo canal Paola Aleksandra. Disponível em: https://www.youtube.com/watch?v=EEVnc53OXoU. Acesso em: 18 mai. 2020.

JULLIAN, Juan. Querido ex, (que acabou com a minha saúde mental, ficou milionário e virou uma subcelebridade). $1^{\mathrm{a}}$ ed. [s.1.]: Transversal, 2019. E-book.

LEITE, Tatiany. Quem é o maior nome de literatura YA aqui no Brasil pra vocês? [s.1.], 2019. Twitter: @atatianyLeite. Disponível em: https://twitter.com/atatianyLeite/status/1159540571612045313. Acesso em: 09 mai. 2020.

LITERALIZE. Conheça um novo mundo. [s.1.], [2019?]. Disponível em: https://literalize.carrd.co/. Acesso em: 09 mai. 2020.

LITERALIZE. Editora Literalize. [s.1.], 2019. Twitter: @ed_literalize. Disponível em: https://twitter.com/ed_literalize. Acesso em: 09 mai. 2020.

LUFT, Gabriela. "A literatura juvenil brasileira no início do século XXI: autores, obras e tendências". Estudos de Literatura Brasileira Contemporânea, n. 36. Brasília, julho-dezembro de 2010, p. 111-130. Disponível em: https://periodicos.unb.br/index.php/estudos/article/view/9712. Acesso em: 09 mai. 2020.

MARTINS, Vitor. me sentindo validado demais (...).2018a. Twitter: @vitormrtns. Disponível em: https://twitter.com/ vitormrtns/status/1073190405594853376. Acesso em: 10 mai. 2020.

MARTINS, Vitor. mta gente na minha timeline está falando a respeito (...).2018b. Twitter: @vitormrtns. Disponível em: https://twitter.com/vitormrtns/status/986323645495758849. Acesso em: 10 mai. 2020.

MARTINS, Vitor. Quinze dias. Rio de Janeiro: Globo Alt, 2017. E-book.

MARTINS, Vitor. Um milhão de finais felizes. Rio de Janeiro: Globo Alt, $2018 \mathrm{c}$.

NMC \#266 - Querido ex. Locução de Thiago Arzakom, Heitor Gomez, Mateus Benevenuti e Juan Jullian. Não Me Critica, junho de 2019. Podcast. Disponível em: https://open.spotify.com/episode/5tNxcUUbR38TTkAfJLcJZn?si=6RQmsAGkRNqKKbeiCw6SFw. Acesso em: 09 mai. 2020. 
PÁGINA 7. Sobre Página 7 Agência Literária. [s.1.], 2016. Disponível em: http://agenciapag7.com.br/?page id=49. Acesso em: 10 mai. 2020.

PATEE, Amy. Between Youth and Adulthood: Young Adult and New Adult Literature. Children's Literature Association Quarterly, v.42, n.2, Summer 2017, pp. 218-230, Johns Hopkins University Press. Disponível em: https://muse.jhu.edu/ article/660188/pdf. Acesso em: 01 mai. 2020.

RECORD. Galera. [s.1.], [2019?]a. Disponível em: https://www.record.com.br/editoras/galera/. Acesso em: 18 mai. 2020.

RECORD. Verus. [s.1.], [2019?]b. Disponível em: Verus: https:/www.record.com.br/editoras/verus/. Acesso em: 18 mai. 2020.

ROCCO. Rocco Jovens Leitores. [s.1.], [2014?]. Disponível em: https://www.rocco.com.br/selo/rocco-jovens-leitores/. Acesso em: 09 mai. 2020.

ROCHA, Lucas. Você tem a vida inteira. Rio de Janeiro: Galera Record, 2018a.

ROCHA, Lucas. "Você tem a vida inteira", de Lucas Rocha. Record, 15 de agosto de 2018. 2018b. Disponível em: https://www.record.com.br/voce-tem-a-vida-inteira-de-lucas-rocha/. Acesso em: 11 mai. 2020.

SEGUINTE. Página inicial. [s.1.], [201-?]. Disponível em: https://www.editoraseguinte.com.br/. Acesso em: 20 mai. 2020.

SEGUINTE. O selo é oferecido por um grupo... [s.1.], 2020. Twitter: @editoraseguinte. Disponível em: https://twitter. com/editoraseguinte/status/1223360577373974528. Acesso em: 26 mai. 2020.

TRITES, Roberta. Disturbing the Universe: Power and Repression in Adolescent Literature. Iowa: University of Iowa Press, 2004.

UM MILHÃO de finais felizes | YA Nacional, 2019. 1 vídeo (5 min). Publicado pelo canal Eduardo Cilto. Disponível em: https://www.youtube.com/watch?v=irb-gopDWqk. Acesso em: 02 mai. 2020. 